\title{
Aircraft Triggered Lightning Caused by Winter Thunderclouds in the Hokuriku Coast, Japan - A Case Study of a Lightning Strike to Aircraft below the Cloud Base-
}

\author{
Fumiaki Kobayashi, Takatsugu Shimura, and Kazutoshi Masuda \\ Department of Geoscience, National Defense Academy, Yokosuka, Japan
}

\begin{abstract}
A case of aircraft triggered lightning, which occurred below the cloud base, was observed at Komatsu Airbase along the coast of the Sea of Japan during the intensive observation period using Doppler radar. The aircraft triggered lightning was accompanied by winter thunderclouds with graupel precipitation in the dissipating stage. The aircraft triggered lightning was initiated by a bi-directional leader. Lightning channels from the aircraft propagated simultaneously both upward and downward with return strokes. The surface electrical field was relatively weak $(10 \mathrm{kV} / \mathrm{m})$ compared with that of natural CG lightning.
\end{abstract}

\section{Introduction}

Lightning that strikes aircraft is an important concern for aircraft operations. Lightning triggered by aircraft (hereafter: "aircraft-triggered lightning") occurs primarily in winter thunderclouds. Aircraft-triggered lightning occurs in and around inactive Cloud-toGround (CG) lightning winter thunderclouds during a cold air outbreak period (Murooka 1986). The frequency of aircraft-triggered lightning is greatest along the coast of the Sea of Japan during the winter than in any other area or during any other season. One of the highest frequency areas of aircraft-triggered lightning is the Hokuriku District. According to the Pilot Report (PIREP), on average, more than 30 cases of aircrafttriggered lightning that hit commercial airliners are reported during one mid-winter season around the Komatsu Airbase (hereafter termed KA) in the Ishikawa Prefecture, Japan. However, few reports of the aircrafttriggered lightning have been documented, because the aircrafts were often struck by lightning in the cloud far from the runway (e.g., Shimura et al. 1996).

Moreover, it is difficult to forecast or even "nowcast" aircraft-triggered lightning risk, since wintertime thundercloud characteristics differ from summertime thundercloud characteristics (Brook et al. 1982; Kawasaki and Mazur 1992; Kitagawa and Michimoto 1994). For example, wintertime thunderclouds have a lower cloud top ( 3 to $5 \mathrm{~km}$ in height), a lower cloud base (about $500 \mathrm{~m}$ ), and a smaller horizontal scale. Aircrafttriggered lightning is generated during an outbreak of cold air, when few or no natural CG lightning are observed.

Many aircraft-triggered lightning events occur in the cloud as well as during take-off and landing. Aircraft-triggered lightning below the cloud base has

Corresponding author: Fumiaki Kobayashi, Department of Geoscience, National Defense Academy, Hashirimizu, Yokosuka 239-8686, Japan.E-mail: kobayasi@nda.ac.jp. @2007, the Meteorological Society of Japan. often been reported (Mazur 1989). However until recently, the relationship between aircraft-triggered lightning and thundercloud structures has not been understood, since there has been a lack of picture or video images of aircraft-triggered lightning, along with a lack of detailed radar echo data. On 6 January 1997, we succeeded in taking a video of aircraft-triggered lightning strikes, as well as the Doppler radar data. In this paper, the relationship between radar echo structure and the aircraft-triggered lightning is discussed in order to clarify which part of the winter thunderclouds causes the aircraft-triggered lightning.

\section{Doppler radar observations}

The observation of winter thunderclouds was conducted along the Hokuriku Coast of Japan from December to January in winter seasons. X-band Doppler radar observation of winter thunderclouds, which are generated and develop near the coast, was carried out at KA. Figure 1 shows the topography of the Hokuriku District, as well as the radar observational range, a circle of radius $64 \mathrm{~km}$. KA is located in the Hokuriku District, $5 \mathrm{~km}$ from the coast facing the Sea of Japan. To observe the fine structure of the thunderclouds that generate aircraft-triggered lightning, short-range observation of Plane Position Indicator (PPI) and Range Height Indicator (RHI) scans were performed. In order to investigate the lower part of the thunderclouds, the PPI elevation was set to $1.8^{\circ}, 3.6^{\circ}$, and $5.4^{\circ}$. Simultaneous RHI images were obtained that allowed the observation of the vertical structure of the thunderclouds above KA. The RHI azimuths were set to $226^{\circ}, 232^{\circ}, 238^{\circ}$, and $270^{\circ}$, since the aircraft primarily take-off in the southwest direction $\left(240^{\circ}\right)$. The PPI and RHI images were obtained every 7 -minute intervals. The $\mathrm{X}$-band radar had the following specifications: a frequency of $9.4 \mathrm{GHz}$, a wavelength of $3 \mathrm{~cm}$, a beam width of $2^{\circ}$, a minimum range (intensity) of $16 \mathrm{dBZ}$, a spatial resolution in the radial direction of $125 \mathrm{~m}$, and an antenna scan speed of $1 \mathrm{rpm}$.

Using a handheld $8 \mathrm{~mm}$ video camera recorder, we took video footage of the aircraft that took off and approached KA. A member of the intensive observation (author K. M.) observed all aircraft during take off and landing at the radar site near the runway on the day. Sampling of graupel particle was carried out during take off and landing period. Surface electrical field and lightning detection equipment were also used in this study. Lightning detection was performed by a VHF direction finding system at KA and the lightning location system (LLS) of Hokuriku Electric Power Company.

\section{A case study on 6 January 1997}

A synoptic low system was moving northeastward 


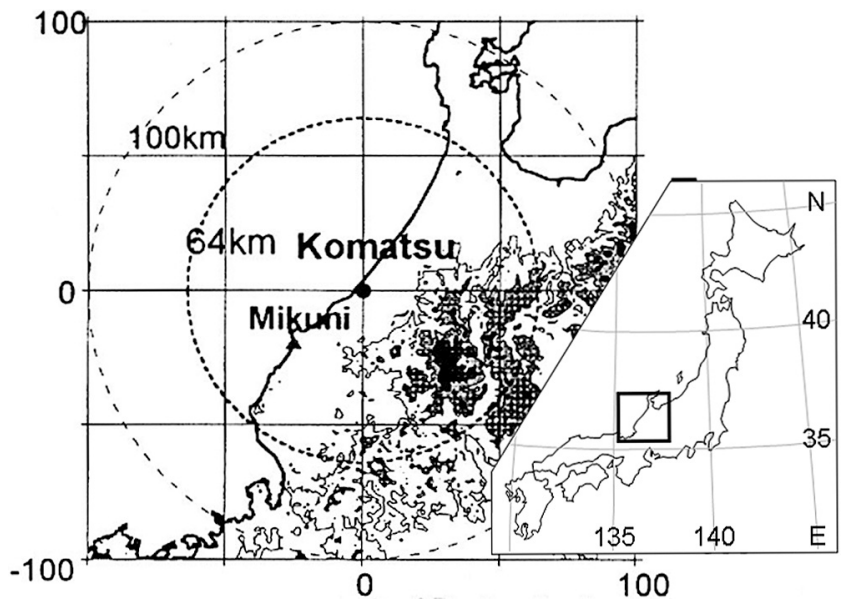

Fig. 1. The locations of the Doppler radar site (Komatsu) in Hokuriku. Circles show radar ranges.

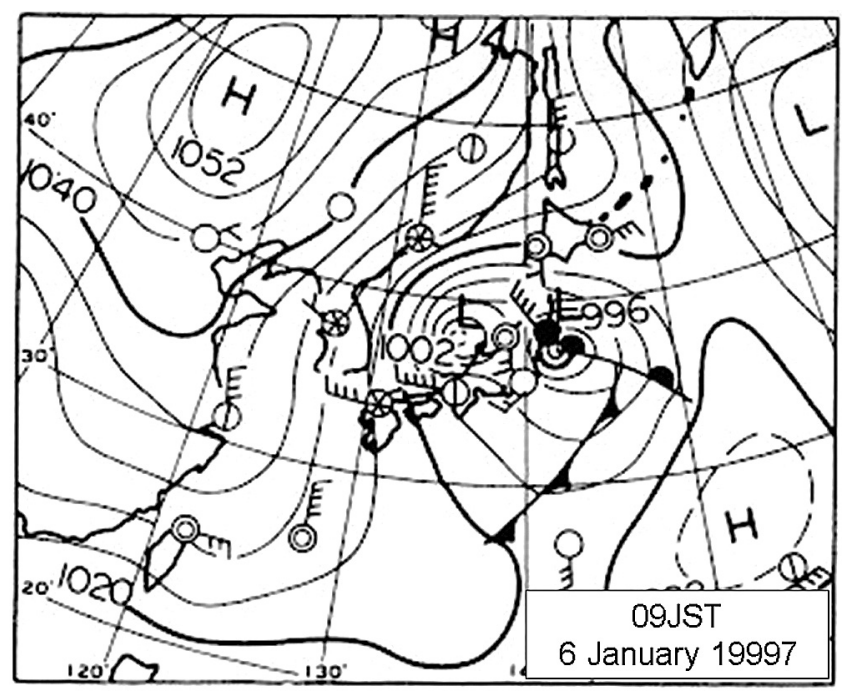

Fig. 2. Surface weather map at 09:00 JST on 6 January 1997.

along the Pacific side of Japan, with a sub-low (meso$\alpha$-scale low) pressure system over the Sea of Japan (Fig. 2 ). This mesoscale low over the Sea of Japan was accompanied by a cold air mass with temperature of $-30^{\circ} \mathrm{C}$ (about $500 \mathrm{hPa}$ ). After the passage of the mesoscale low, a high to the west and a low to the east winter monsoon pressure pattern became dominant over the Sea of Japan. During the day, intermittent rain and snow showers with graupel were observed at KA. According to the LLS and optical observation at KA, no lightning flashes occurred 1 hour before or after this event.

Figure 3 shows a picture of the aircraft-triggered lightning recorded on the $8-\mathrm{mm}$ video camera. This frame of the video image shows upward and downward branching leaders, which started from the aircraft simultaneously. The upward leader propagated with branching from the head of the aircraft (around the cockpit), and the downward leader propagated with branching from the tail (around the stabilizer). After this image, the lightning channel associated with the

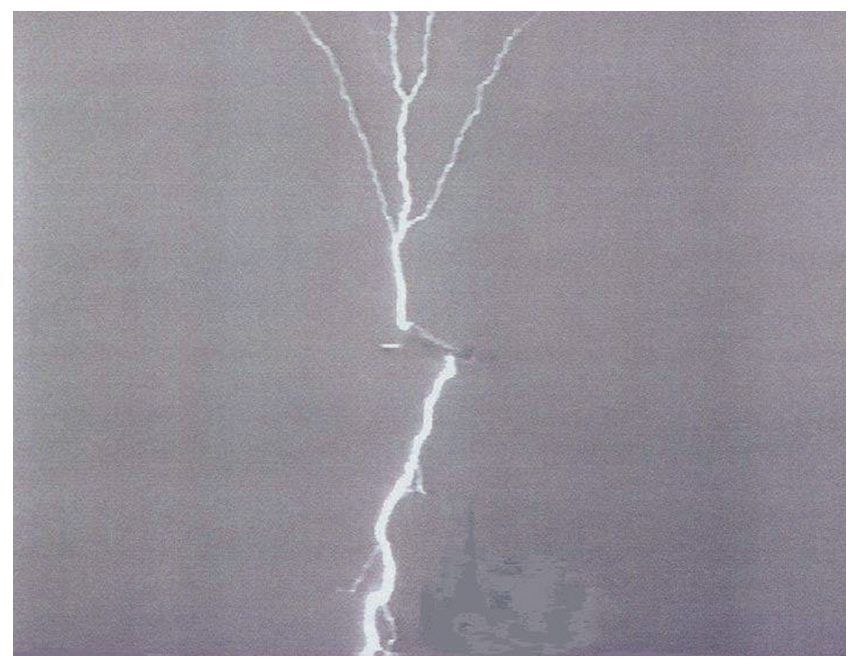

Fig. 3. Video image of aircraft-triggered lightning at Komatsu Airbase at 11:59:57 JST on 6 January 1997.

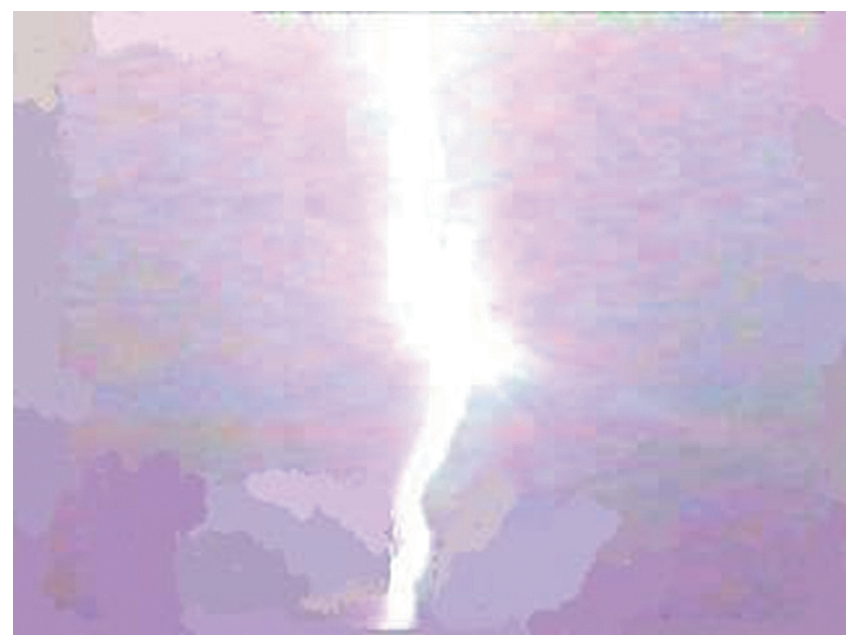

Fig. 4. The return stroke of the lightning about 0.2 second after Fig. 3.

return stroke was observed (Fig. 4, the video image of Supplement 1). From these images, it is reasonable to assume that this lightning strike was triggered by the aircraft, and hence is an example of aircraft-triggered lightning. Based on the video images, the aircraft track, and the height of the cloud base, the aircraft height during the event was assumed to be about 500 m AGL. The height of the cloud base observed at the radar site was about $600 \mathrm{~m}$ AGL. The aircraft entered the thundercloud just after the lightning.

Figure 5 shows a time sequence of the PPI radar echo images before and at the lightning on 6 January 1997. There were scattered cell-like radar echoes near the coast in the Sea of Japan. After 11:42 JST (Japan Standard Time), some of them formed band shaped echoes about $50 \mathrm{~km}$ in length with a maximum reflectivity of about $30 \mathrm{dBZ}$. At 11:48 JST, an echo cell developed near the coastline and the echo intensity reached over $40 \mathrm{dBZ}$. After that, the cell continued to increase its echo core area (> $40 \mathrm{dBZ})$ as it moved eastward at a 

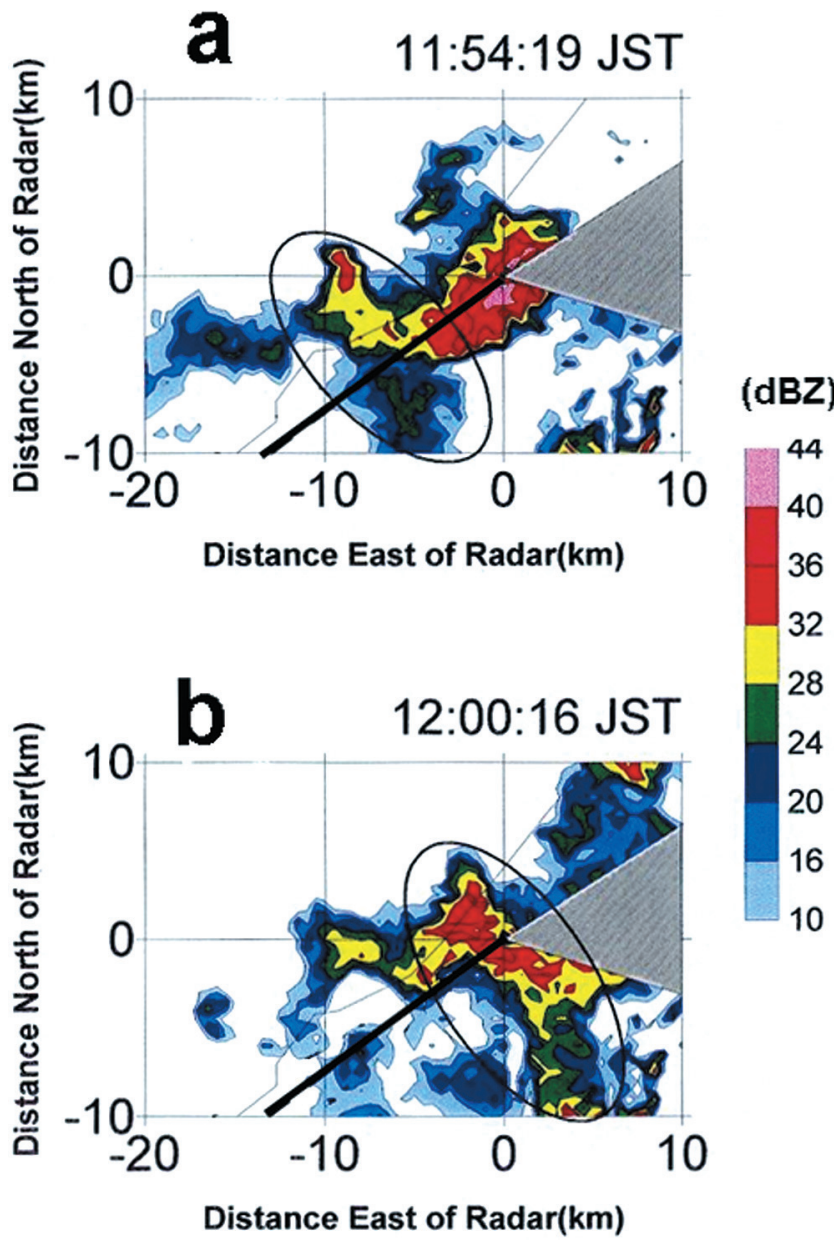

Fig. 5. Time sequence of radar echo images (reflectivity) at 11:54 JST and 12:00 JST (PPI 1.8 ${ }^{\circ}$. Solid lines denote the direction of RHI scans in Fig. 6. Circles denote the radar echo cell, which caused the aircraft-triggered lightning.
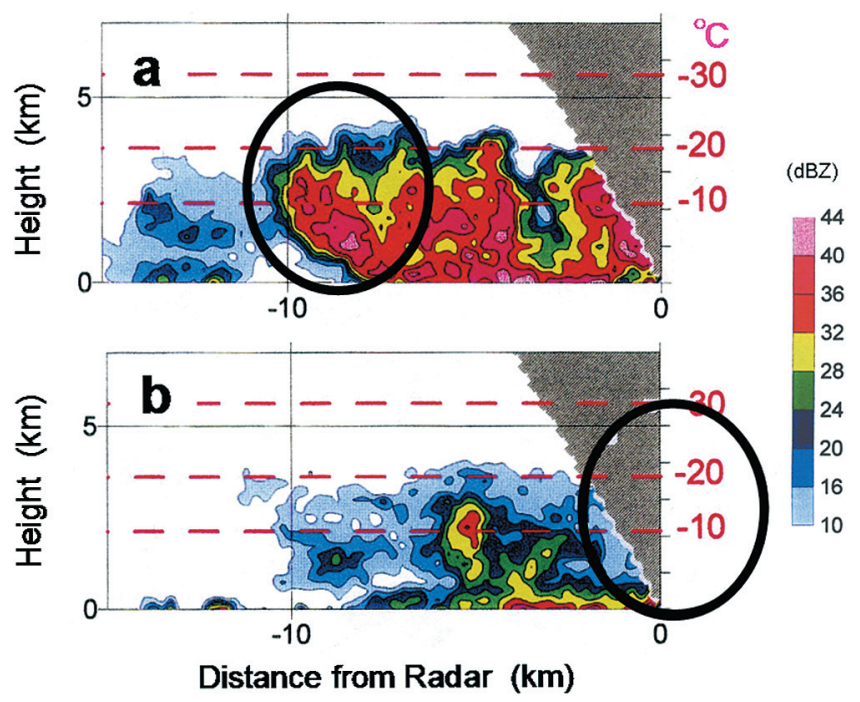

Fig. 6. RHI radar echo images (azimuth of $232^{\circ}$ ) before and during the aircraft-triggered lightning. (a): 11:51 JST. (b): 11:57 JST.

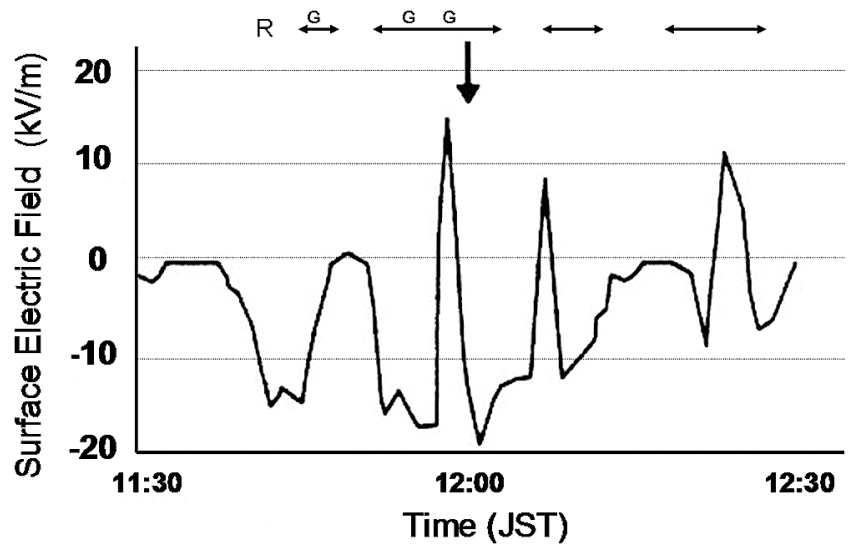

Fig. 7. Temporal change of surface electrical record at KA. Letters $R$ and $G$ indicate duration of rainfall and precipitation of graupel particle, respectively. A bold arrow denotes the time of the lightning.

speed of $80 \mathrm{~km} / \mathrm{hr}$. At 11:54 JST, the cell passed over KA and a new cell developed behind the cell (a circle in Fig. 5a). The west edge of the cell with a reflectivity over $40 \mathrm{dBZ}$ passed over KA at 12:00 JST (Fig. 5b). Graupel precipitation, $1 \mathrm{~cm}$ in diameter, with rain showers was observed at the radar site of KA from 11:55 to $11: 57 \mathrm{JST}$. Visibility was about $5 \mathrm{~km}$ during the precipitation. After the precipitation ended, an aircraft started to leave the airbase at 11:58:00 JST and took off at 11:59:40 JST. The aircraft-triggered lightning occurred at 11:59:57 JST, just after take off from KA.

Figure 6 shows the RHI images before and during the time of the aircraft-triggered lightning along the solid line $\left(232^{\circ}\right)$ shown in Fig. 5. At 11:51 JST, the height of the echo top reached up to $3 \mathrm{~km}$, the $-20^{\circ} \mathrm{C}$ level, and after about 10 minutes later, the strong echo region with $32 \mathrm{dBZ}$, disappeared except below the $1 \mathrm{~km}$ height. The low altitude strong echo area indicates the bright band and ground clutter (Fig. 6b). From these results, it was involved that the increase in the reflectivity at low elevations (PPI 1.8 image of Fig. 5b) was associated with the disappearance of the strong echo region during its dissipating stage. At take off, graupel with a diameter of $5 \mathrm{~mm}$ was observed approaching this echo cell. Downdraft calculated by Doppler velocity pattern using VAD method was about $3 \mathrm{~m} \mathrm{~s}^{-1}$ near the cloud base.

\section{Discussion and concluding remarks}

Figure 7 shows the temporal change of the electrical field at KA, which collected every 90-second intervals. The electrical field had the positive peak value before the lightning event accompanied with the graupel precipitation. Positive electrical field defines as downward direction. Although, the peak value of the electrical field reached over $10 \mathrm{kV} / \mathrm{m}$ before the lightning event, this peak value was smaller than that seen in other natural CG lightning cases of winter thunderclouds around KA. For example, Michimoto (1993) observed surface electrical value over $40 \mathrm{kV} / \mathrm{m}$ during natural CG lightning.

Tomine et al. (1987) pointed out the method to prevent lightning to an aircraft. They concluded that the aircrafts must keep a distance from a strong echo core of winter thunderclouds and from the high value region of surface electric field. However, aircraft- 
triggered lightning is not natural CG, but triggered lightning like a lightning to a tall chimney in winter season is.

Meteorological observations using a Doppler radar at KA, located on the Hokuriku Coast, were carried out to investigate winter thunderclouds that cause aircrafttriggered lightning. A case of aircraft-triggered lightning, which occurred below the cloud base, was observed on 6 January 1997. This paper is the first to document the direct observation of aircraft-triggered lightning in Hokuriku Coast. The features of winter thunderclouds that cause aircraft-triggered lightning were presented. The conclusions of this study are as follows:

(1) The aircraft-triggered lightning was accompanied by inactive $\mathrm{CG}$ lightning winter thunderclouds, which had no CG lightning. The aircraft-triggered lightning occurred below the cloud base $(500 \mathrm{~m}$ AGL), around a decaying winter thundercloud in cold air outbreak.

(2) The aircraft-triggered lightning is caused by winter thunderclouds with graupel precipitation and occurred in downdraft region. The surface electrical field was relatively weak $(10 \mathrm{kV} / \mathrm{m})$ compared with that of natural CG lightning.

(3) The aircraft-triggered lightning was initiated by a bi-directional leader. Lightning channels from the aircraft propagated simultaneously both upward and downward, relatively.

\section{Acknowledgments}

The authors wish to offer thanks to Dr. R. Misumi (National Research Institute for Earth Science and Disaster Prevention) and anonymous reviewers for their valuable comments.

\section{Comments and supplements}

1. Video image of the aircraft-triggered lightning in this case study is shown in Supplement 1.

\section{References}

Brook, M., M. Nakano, P. Krehbiel, and T. Takeuchi, 1982: The electrical structure of the Hokuriku winter thunderstorms, J. Geophys. Res., 87, 12071215.

Kawasaki, Z., and V. Mazur, 1992: Common physical processes in natural and triggered lightning in winter storms in Japan, J. Geophys. Res., 97, 1293512945.

Kitagawa, N., and K. Michimoto,1994: Meteorological and electrical aspects of winter thunderclouds, $J$. Geophys. Res., 99, 10713-10721.

Mazur, V., 1989: A physical model of lightning initiation on aircraft in thunderstorms, J. Geophys. Res., 94, 3326-3340.

Michimoto, K., 1993: A study of radar echoes and their relation to lightning discharge of thunderclouds in the Hokuriku district, Part II: Observation and analysis of "one-flash" thunderclouds in midwinter, J. Meteor. Soc. Japan, 71, 195-204.

Murooka, Y., 1986: Lightning strike to aircraft. Meteorological Research Note, 154, 76-80, (in Japanese).

Shimura, T., F. Kobayashi, K. Michimoto, K. Nagaya, and T. Sakai, 1996: A Doppler radar study of lightning to the aircraft. Technical Report of Electric Discharge and High Volutage, ED-96-187, HV-9687, 9-16, (in Japanese).

Tomine, K., M. Suzukawa and K. Michimoto, 1987: An available method to prevent lightning on aircrafts using electric field on the surface. Tenki, 34, 769773, (in Japanese).

Manuscript received 17 July 2007, accepted 12 October 2007

SOLA: http://www.jstage.jst.go.jp/browse/sola/ 